\title{
Modified coronectomy procedure for mandibular third molar: association of platelet-rich fibrin
}

\author{
Técnica de coronectomia de terceiro molar inferior \\ modificada: associação de plasma rico em fibrina
}

\author{
Ronaldo Célio MARIANO' ${ }^{1}$ iD https://orcid.org/0000-0001-7334-8276 \\ Alexandre Augusto Ferreira da SILVA ${ }^{1}$ iD https://orcid.org/0000-0001-8470-7422 \\ Guilherme Menali GOMES1 ${ }^{1}$ https://orcid.org/0000-0003-1662-3686 \\ Luis Henrique Theodoro ALVES1 ID https://orcid.org/0000-0003-4414-1465 \\ Marina Reis OLIVEIRA² iD https://orcid.org/0000-0002-1952-0730
}

\begin{abstract}
The present case report describes a modified technique of coronectomy for mandibular third molar with association of Platelet-Rich Fibrin Graft (PRF). The panoramic radiograph showed proximity of the roots of the vertical positioned 48 tooth with the superior wall of the mandibular canal, since the erasure of the superior cortical of the mandibular canal was observed. Due to the risk of injury to the inferior alveolar nerve, the technique of coronectomy was chosen. After the realized the coronectomy, in order to promote the regeneration of soft and hard tissues and also to prevent pulp changes that could lead to pain, pulp necrosis and infection, the PRF graft was used to fill the surgical defect formed by removal of the crown. Good healing evolution was observed and after 12 months of clinical and radiographic follow-up there was complete bone formation in the area where the crown was removed and no complications were observed.
\end{abstract}

Indexing terms: Dentistry. Molar, third. Surgery oral.

\section{RESUMO}

O presente caso clínico descreve uma técnica modificada de coronectomia de um terceiro molar inferior com a associação de Plasma Rico em Fibrina (PRF). A radiografia panorâmica mostrou proximidade das raízes do dente 48 posicionado verticalmente com a cortical superior do canal mandibular, The panoramic radiograph showed proximity of the roots of the vertical positioned 48 with the superior wall of the mandibular canal, ma vez que, observou-se o desaparecimento da cortical superior do canal. Devido ao risco de lesão ao nervo alveolar inferior, a técnica de coronectomia foi empregada. Depois de realizada a coronectomia, com o objetivo de favorecer a regeneração dos tecidos moles e duros e também de prevenir alterações pulpares que poderiam causar dor, necrose pulpar e infecção, o enxerto de PRF foi usado para preencher o defeito formado pela remoção da coroa. Boa evolução cicatricial foi observada 12 meses pós-operatórios, o acompanhamento clínico e radiográfico mostrou completa formação óssea na área onde a coroa foi removida e não foram observadas complicações.

Termos de indexação: Odontologia. Dente serotino. Cirurgia bucal.

\section{$\boldsymbol{\nabla} \boldsymbol{\nabla} \boldsymbol{\nabla}$}

1 Universidade Federal de Alfenas, Faculdade de Odontologia. Alfenas, MG, Brasil.

2 Universidade Estadual Paulista, Faculdade de Odontologia de Araraquara. Rua Humaitá, 1680, 14903-060, Araraquara, SP, Brasil. Correspondence to: MR OLIVEIRA. E-mail: <marinareis89@hotmail.com>.

$\boldsymbol{v} \nabla \boldsymbol{v}$

How to cite this article

Mariano RC, Silva AAF, Gomes GM, Alves LHT, Oliveira MT. Modified Coronectomy procedure for mandibular third molar: association of platelet-rich fibrin. RGO, Rev Gaúch Odontol. 2021;69:e20210040. http://dx.doi.org/10.1590/1981-863720210004020200050 


\section{INTRODUCTION}

The extraction of impacted third molars is one of the most common oral surgical procedures due to the complications that this situation can cause, such as: caries, pericoronitis, periodontal disease [1]. However, it must be considered that, although performed so routinely, this procedure also involves risks due to the positioning of the third molars in relation to the important anatomical structures. Temporary injury to the inferior alveolar nerve during extraction of lower third molars, e.g., occurs in about $8 \%$ of cases and permanent injury in $3.6 \%$ of cases $[2,3]$.

Due to the morbidity caused by injury to the inferior alveolar nerve, it is very important to consider the risks and benefits of the surgical procedure in the preoperative planning, so that the patient is treated in the best possible way and the risk of nerve damage is reduced [4]. In this context, it is important to note that coronectomy or "intentional retention root", which consists of removing only the crown of the tooth and keeping the root intact, is an alternative procedure to complete extraction of the tooth. This procedure is especially interesting in cases of third molars that have direct contact with the mandibular canal [4-6]. The coronectomy was first described in 1989 by Knutsson et al. [7], however, it is not yet a popular procedure because there are few studies on the subject and therefore the results of short-term and long-term follow-up are scarce [8].

Despite this, the treatment of nerve injury after complete removal of mandibular third molars is difficult and often unpredictable. Therefore, coronectomy is a viable alternative to minimize the risk of injury to the inferior alveolar nerve, in cases in which there is proximity and/or contact of the roots of mandibular third molars with the mandibular canal $[4,5]$. In the first randomized clinical study about inferior alveolar nerve injury during complete extraction of the tooth or during coronectomy, a significantly lower rate was observed with coronectomy. However, it is important to emphasize that the coronectomy technique must be performed correctly to avoid injury to the inferior alveolar nerve, since, according to Renton et al. [9] Leung \& Cheung [5], the rate of nerve injury in coronectomy performed incorrectly is similar to that observed with complete removal of the tooth.

As the technique of coronectomy is not yet widely used, the description of graft association to the technique is also scarce in the literature. Therefore, it is believed that the use of platelet-rich fibrin (PRF) may be a good option, since it is an autologous product, low cost and without risk of allergic reactions [10]. In addition, besides favoring the regeneration of soft and hard tissues [11], PRF can also be used to aid in the regeneration of periodontal [12] and pulp [13]. This latter application of PRF is interesting in coronectomy because it could help prevent pulpal changes and consequently prevent Need for surgical reintervention to remove the root fragment. Thus, the description of the present clinical case is important, as it reports the use of PRF after coronectomy of a third lower molar and this association, according to our knowledge, is unpublished in the literature.

\section{CASE REPORT}

A 20-year-old male, a non-smoker patient, was referred for extraction of the impacted third molars. On clinical examination, tooth 48 was semi-erupted, with distal cusps partially covered with inflamed gingival tissue (figure 1). The patient reported having had other episodes of pericoronaritis. At the first visit the patient presented a panoramic radiograph showing the 48 with curved and fully formed roots, involving the mesial and distal roots and disappearance of the upper cortical of the mandibular canal (figure 2). Due to the obvious risks of root fractures, damage to the lower alveolar vascular-nervous bundle, the patient received the option of coronectomy associated with the PRF graft in order to minimize nerve damage, adding the tissue regenerative effect produced by PRF.

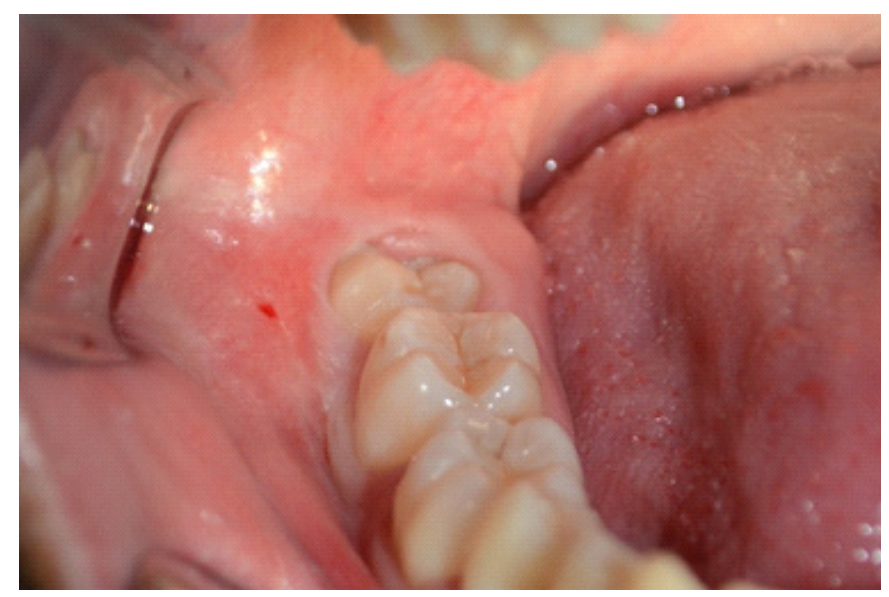

Figure 1. Tooth 48 was semi-erupted, with distal cusps partially covered with inflamed gingival tissue. 


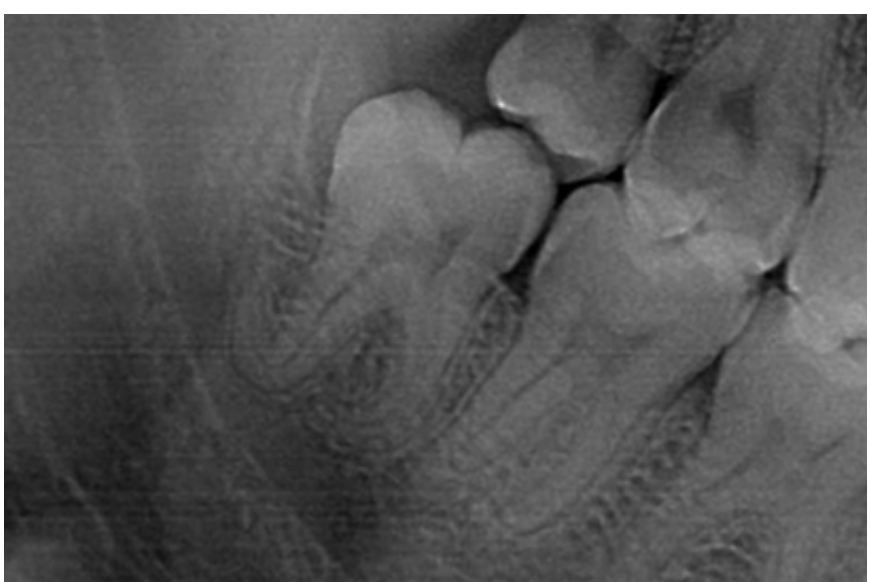

Figure 2. Radiograph showing the 48 with curved and fully formed roots and disappearance of the upper cortical of the mandibular canal.

The patient, allergic to penicillin, was medicated with azithromycin 500mg preoperatively, dexamethasone $4 \mathrm{mg}$, dipyrone potentiated (Dipirone, prometazine, adiphenine) and chlorhexidine mouth washes. Under local anesthesia, the modified Avelanal incision with subsequent soft tissue divulsion allowed to expose the 48th crown to the beginning of the corono-radicular section with high-speed coupled drills (figure 3A). The drill 701, inserted at an angle of approximately $45^{\circ}$, allowed to section the crown completely prior to its removal. Complementation of crown wear with spherical diamond drill was performed to leave the radicular remnant in an infra-osseous position to respect the margin at least $3 \mathrm{~mm}$ below the alveolar crest recommended by Pogrel et al. [14] (figure 3B). The height of the bone margins was maintained intact, also ensuring that the drill did not reach the cortical lingual to avoid damage to the lingual nerve.

Immediately after removal of the crown of 48 , without any type of dental dislocation, the PRF obtained

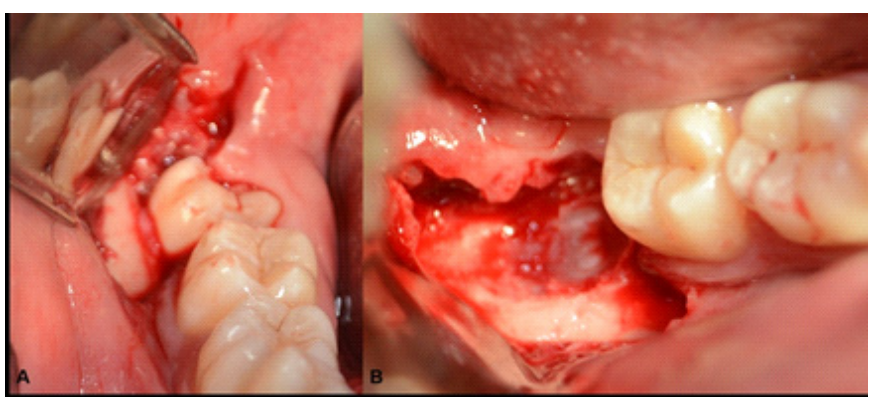

Figure 3. Soft tissue divulsion allowed to expose the 48th crown (A). Coronectomy performed according Pogrel et al. [14]. after single centrifugation [15] (Figure 4A) was inserted over the roots (figure 4B) and the soft tissues were immediately sutured with 5-0 nylon. The use of azithromycin was prolonged for 6 days, chlorhexidine $0.12 \%$ mouth washes for 14 days and the analgesic was made available in the case of painful symptomatology. There was a good healing evolution and after clinical and radiographic proservation of 12 months postoperative, complete bone formation was observed in the region where the crown was removed and no complications were observed in this period (figure $5 A$ and $B)$.

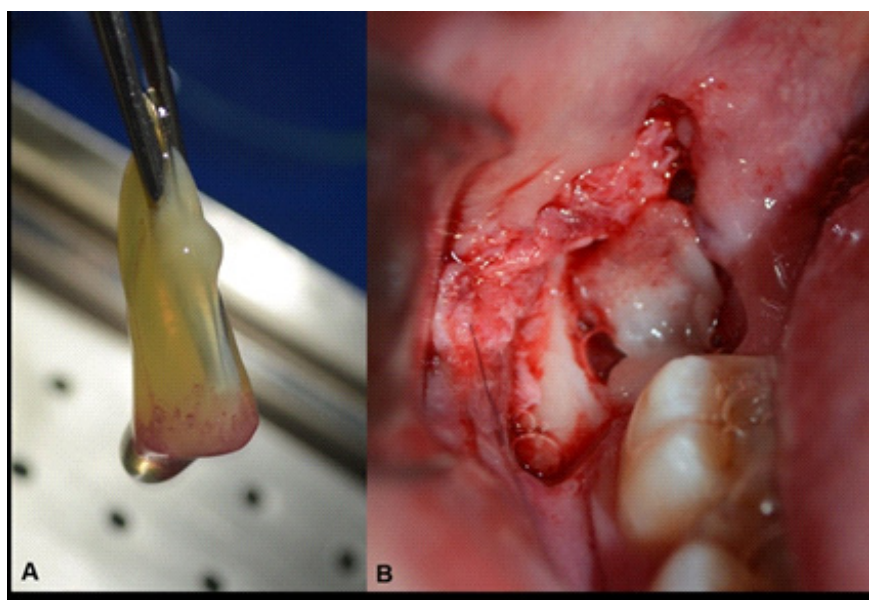

Figure 4. PRF obtained after single centrifugation (A). PRF inserted over the roots $(B)$

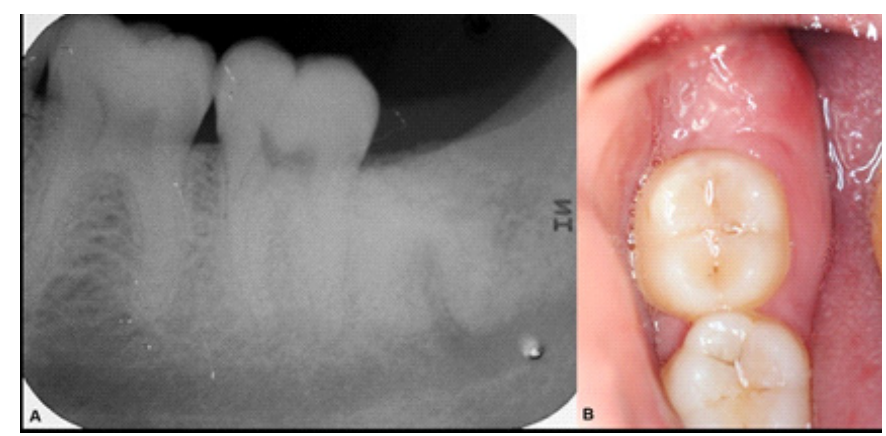

Figure 5. Clinical and radiographic proservation of 12 months postoperative ( $A$ and $B)$.

\section{DISCUSSION}

Neurological lesions during the extraction of mandibular third molars can be caused by nerve compression 
during extractive movements when the extractors are used, or even by the section of the vascular-nervous bundle by rotating instruments during the surgical procedure [16]. As an alternative to prevent risk of lesions in the inferior alveolar nerve, assisted orthodontic extraction is a technique that reduces risks, however, there is a need to wait longer to perform the surgical procedure and also greater financial costs for the patient [17]. Another possibility for minimizing the risk of injury to inferior alveolar nerve is the coronectomy. In 2010, this technique was accepted as a standard procedure in the USA at the multidisciplinary conference of third molars. Despite this, it is still a procedure that generates controversy and is not considered as a treatment option by some surgeons $[18,19]$. In contrast, several studies have shown good results in this technique to prevent injury to the inferior alveolar nerve $[4,14,19]$.

However, it is not an applicable technique in all cases. Teeth with infectious processes, mobility, presence of root caries or teeth in which it is not possible to remove the entire enamel portion should not undergo coronectomy. In addition, coronectomy is more indicated for vertical or mesioangulated teeth. In teeth positioned horizontally along the inferior alveolar nerve, transection of the nerve during crown cut may occur $[14,20]$. In the present case, although the patient reported episodes of pericoronaritis, the condition was treated before the procedure, and at the time of coronectomy there was no infection. In addition, the tooth was positioned vertically, which is the ideal position for performing the procedure.

Regarding the technique of coronectomy, the classic technique consists of the total separation between the crown and the dental root, removal of all the enamel and wear of the coronary remnant until there is a quantity of bone at the crests of 2 to $3 \mathrm{~mm}$ above the crown. A variation of the initial technique was proposed by Renton [21] and also used by Goto et al. [22] in which he does not make use of the protective instrument by the lingual, and the drill when performing the odontosection does not reach the entire depth of the crown remaining below the lingual region, reaching two-thirds of the crown length in vestibular-lingual direction, protecting and avoiding damage to the lingual nerve. The crown is separated by a delicate extractor suggested by the author. However, this alternative technique may present faults and the risk of root movement is high and if this occurs, it is necessary to extract the roots. Therefore, the risk of injury in inferior alveolar verve becomes similar to that of conventional extraction, making the use of this technique very questionable. In another variant of the initial technique, it is suggested that the crown be vertically sectioned in small parts using high-speed drills or discs up to the cement-enamel junction and then the remaining enamel smoothing and removal and root planing [20]. However, in order to reduce the chances of root dislocation, in the present case, we chose the classic coronectomy technique proposed by Pogrel et al. [14] in 2004.

Regarding preoperative planning, it is important to note that panoramic radiography is still the most commonly used imaging test for the preoperative planning of third molar extraction [4]. Since the deviation of the mandibular canal, the darkening or disappearance of the cortical of the canal walls and the deflection of the roots are indicative of possible nerve damage during the exodontia [23]. In the present clinical case, with panoramic radiography, it was observed that the roots were totally formed with marked flexure in the mesial and distal and erasure of the superior cortical of the mandibular canal.

Although it is an acceptable procedure to avoid nerve injury, there is concern about the risk of complications with coronectomy due to the lack of scientific evidence on the subject [8]. However, Martin et al. [24] carried out a systematic review of the literature in which they observed a low rate of complications. In this study, the lesion of the inferior alveolar nerve varied from 0 to $9.5 \%$ and of the lingual nerve from $0 \%$ to $2 \%$. The frequency of other complications, such as postoperative pain (1.1 to $41.9 \%)$, swelling (4.6\%), alveolitis (2 to $12 \%$ ), infection ( 1 to $9.5 \%)$ and pulp disease $(0.9 \%$ ) was also evaluated. Radicular migration, in turn, was a common finding that ranged from $2 \%$ to $85.3 \%$ of cases depending on the study [24]. In contrast, in the present study, none of the cited complications were observed so far. In this context, it is important to note that, some studies such as those by Leung \& Cheung [5] and Hatano et al. [25] presented higher rates of complications. This can be explained in part by the fact that the authors did not administer antibiotics in the postoperative period. In the case report described in the present study, the patient was medicated with a prophylactic antibiotic and in the postoperative period and no complications were noticed until the follow-up period of 12 months. Similarly, Monaco et al. [26], also administered prophylactic and postoperative antibiotic therapy and observed a low complication rate. 
As for the risk of developing infection around the root, according to Renton et al. [9], there is no difference in the infection rate between coronectomy and total tooth removal. In addition, the success rate of coronectomy is high, ranging from $61.7 \%$ to $100 \%$ [24]. The need for reintervention due to migration or infection ranges from 0 to $12.1 \%[7,9,14,27]$. Renton et al. [9] observed a higher failure rate in coronectomy in female patients and in cases of teeth with conical roots. However, in the present case, good cicatricial evolution and no signs or symptoms of infection were observed after 12 months of coronectomy. Being that, the patient was male and the roots of the teeth were curved.

As for root migration, Pogrel et al. [14] followed 50 cases of coronectomy for 6 months and observed root migration in $30 \%$ of the cases. Migration usually occurs up to 3 months and paralyzes between 12 and 24 months as the bone regenerates and reshapes [5]. Dolanmaz et al. [6], on the other hand, performed 47 coronectomies on lower third molars and observed a mean root migration of $3.4 \mathrm{~mm}$ after 6 months, $3.8 \mathrm{~mm}$ after 12 months and 4 $\mathrm{mm}$ after 24 months. However, in the present case no root migration was observed after 12 months of follow-up.

In order to accelerate bone formation and reduce the risk of complications, in the present case report, PRF was used after coronectomy. Similarly, Leizerovitz \& Leizerovitz [28] also described the association of grafting with the coronectomy technique in order to reduce the formation of periodontal defects in the distal second molar and to avoid root migration. In the work in question, reabsorbable hydroxyapatite was used after coronectomy and a good evolution was observed, without any type of complication after 24 months of follow-up. However, the authors point out that a disadvantage of the technique described by them is the cost of the graft material [28]. Therefore, the use of PRF may be a more interesting alternative, because besides being fully biocompatible it does not make the procedure more expensive, since it is obtained from the patient's own blood.10 Furthermore, with PRF, in addition to favoring the healing of soft and hard tissues [10], there are studies showing beneficial effects on periodontal [12] and pulpal regeneration [13]. This action of PRF on pulp tissue is very interesting after the coronectomy, since in the conventional technique no material is used to protect the freshly cut pulp.

\section{CONCLUSION}

In the present case, the authors propose the use of PRF after coronectomy not only with a view to promoting bone and soft tissue regeneration, but also to avoid pulpal alterations that could culminate in pain, pulp necrosis, infection and need reintervention.

\section{Collaborators}

RC MARIANO: surgical procedure and case documentation. AAF SILVA: helping in the case documentation and literature review. GM GOMES and LHT ALVES: writing of the manuscript. MR OLIVEIRA: critical review of the manuscript and English version.

\section{REFERENCES}

1. Sisk AL, Hammer WB, Shelton DW, Joy ED Jr. Complications following removal of impacted third molars: the role of the experience of the surgeon. J Oral Maxillofac Surg. 1986;44(11):855-859.

2. Black CG. Sensory impairment following lower third molar surgery: A prospective study in New Zealand. N Z Dent J. 1997;93(413):68-71.

3. Smith AC, Barry SE, Chiong AY, Hadzakis D, Kha SL, Mok SC et al. Inferior alveolar nerve damage following removal of mandibular third molar teeth. A prospective study using panoramic radiography. Aust Dent J. 1997;42(3):149-152.

4. Renton T. Update on Coronectomy. A Safer Way to Remove High Risk Mandibular Third Molars. Dent Update. 2013;40(5):362-368.

5. Leung YY, Cheung LK. Safety of coronectomy versus excision of wisdom teeth: A randomized controlled trial. Oral Surg Oral Med Oral Pathol Oral Radiol Endod. 2009;108(6):821-827.

6. Dolanmaz D, Yildirim G, Isik K, Kucut K, Ozturk A. A Preferable Technique for Protecting the Inferior Alveolar Nerve: Coronectomy. J Oral Maxillofac Surg. 2009;67(6):1234-1238.

7. Knutsson K, Lysell L, Rohlin M. Postoperative status after partial removal of the mandibular third molar. Swed Dent J. 1989;13(1-2):15-22.

8. Cilasun U, Yildirim T, Guzeldemir E, Pektas ZO. Coronetomy in patient with high risk of inferior alveolar nerve injury diagnosed by computed tomography. J Oral Maxillofac Surg. 2011;69(6):1557-1561.

9. Renton T, Hankins M, Sproate C, McGurk M. A randomized controlled clinical trial to compare the incidence of injury to the inferior alveolar nerve as a result of coronectomy and removal of mandibular third molars. Br J Oral Maxillofac Surg. 2005;43(1):7-12.

10. Choukroun J, Diss A, Simonpieri A, Girard MO, Schoeffler C, Dohan SL, et al. Platelet-rich fibrin (PRF): a second-generation 
platelet concen-trate. Part IV: Clinical effects on tissue healing. Oral Surg Oral Med Oral Pathol Oral Radiol Endod. 2006;101(3):56-60.

11. Oliveira MR, Silva AC, Ferreira S, Avelino CC, Garcia Júnior IR, Mariano RC. Influence of the association between platelet-rich fibrin and bovine bone on bone regeneration. A histomorphometric study in the calvaria of rats. Int J Oral Maxillofac Surg. 2015;44(5):649-655.

12. Sharma A, Pradeep AR. Treatment of 3-wall intrabony defects in patients with chronic periodontitis with autologous plateletrich fibrin: a randomized controlled clinical trial. J Periodontol. 2011;82(12):1705-1712.

13. Huang FM, Yang SF, Zhao JH, Chang YC. Platelet-rich fibrin increase proliferation and differentiation of human dental pulp cells. J Endod. 2010;36(10):1628-1632.

14. Pogrel MA, Lee JS, Muff DF. Coronectomy: a technique to protect the inferior alveolar nerve. J Oral Maxillofac Surg. 2004;62(12):1447-1452.

15. Dohan DM, Choukroun J, Diss A, Dohan SL, Dohan AJ, Mouhyi J. Platelet-rich fibrin (PRF): a second-generation platelet concentrate. Part I: technological concepts and evolution. Oral Surg Oral Med Oral Pathol Oral Radiol Endod. 2006:101(3):37-44.

16. Gülicher D, Gerlach KL. Sensory impairment of the lingual and inferior alveolar nerves following removal of impacted mandibular third molars. Int J Oral Maxillofac Surg. 2001;30(4):306-312.

17. Kalantar Motamedi MR, Heidarpour M, Siadat S, Kalantar Motamedi A, Bahreman AA. Orthodontic extraction of high-risk impacted mandibular third molars in close proximity to the mandibular canal: a systematic review. J Oral Maxillofac Surg. 2015;73(9):1672-1685.

18. Lieblich SE, Kleiman MA, ZakMJ J. Parameters of care: clinical practice. Guidelines for oral and maxillofacial surgery. (AAOMS ParCare 2012). J Oral Maxillofac Surg. 2012;70:e50.
19. Dodson TB, Cheifetz ID, Nelson WJ, Rafetto LK. Summary of the proceeding of the third molar multidisciplinary conference. J Oral Maxillofac Surg. 2012;70(11):S66-S69.

20. Pogrel MA. Coronectomy: partial odontectomy or intentional root retention. Oral Maxillofac Surg Clin North Am. 2015;27(3):373-382.

21. Renton T. Notes on coronectomy. Br Dent J. 2012;212(7):323-326.

22. Goto S, Kurita K, Kuroiwa Y, Ariji E. Clinical and dental computed tomographic evaluation 1 year after coronectomy. J Oral Maxillofac Surg. 2011;70(5):1023-1029.

23. Leung YY, Cheung LK. Coronectomy of the Lower Third Molar Is Safe Within the First 3 Years. J Oral Maxillofac Surg. 2012;70(7);1515-1522.

24. Martin A, Perinetti G, Costantinides F, Maglione M. Coronectomy as a surgical approach to impacted mandibular third molars: a systematic review. Head Face Med. 2015;11:1-11.

25. Hatano Y, Kurita K, Kuroiwa Y, Yuasa H, Ariji E. Clinical evaluations of coronectomy (intentional partial odontectomy) for mandibular third molars using dental computed tomography: a case-control study. J Oral Maxillofac Surg 2009;67(9):1806-1814.

26. Monaco G, de Santis G, Gatto MR, Corinaldesi G, Marchetti C. Coronectomy: a surgical option for impacted third molars in close proximity to the inferior alveolar nerve. J Am Dent Assoc. 2012;143(4):363-369.

27. O'Riordan BC. Coronectomy (intentional partial odontectomy of lower third molars). Oral Surg Oral Med Oral Pathol Oral Radiol Endod. 2004;98(3):274-280.

28. Leizerovitz M, Leizerovitz O. Modified and grafted coronectomy: a new technique and a case report with two-year followup. Case Rep Dent. 2013;2013:1-7. 